\title{
Risk of venous thromboembolism in hospitalised cancer patients in England-a cohort study
}

\author{
Sonia Ratib ${ }^{1 *}$, Alex J. Walker ${ }^{2}$, Tim R. Card ${ }^{3}$ and Matthew J. Grainge ${ }^{3}$
}

\begin{abstract}
Background: Venous thromboembolism (VTE) is a well-recognised and life-threatening complication in patients with cancer. However, the precise risk of VTE in hospitalised cancer patients in England has not been previously reported.

Methods: We conducted a cohort study using linked Hospital Episodes Statistics and Office for National Statistics mortality data. We determined the risk of VTE separately for 24 cancer sites following first hospitalisation for cancer (index date) and how this varied by age, proximity from hospital admission, administration of chemotherapy and calendar time.

Results: Between 1998 and 2012, 3,558,660 patients were hospitalised for cancer. The cancer sites with the highest risk of VTE during initial hospitalisation for cancer were pancreatic (4.9\%), ovarian (4\%) and liver (3.8\%). The three cancer sites with the highest risk of first VTE event within 6 months from discharge were pancreatic (3.7 \%), oesophagus (3\%) and stomach (2.8\%). For most cancers, the risk of VTE within 6 months from discharge was higher amongst patients who underwent chemotherapy compared to those who did not. The impact of age on risk of VTE varied considerably between cancer sites.
\end{abstract}

Conclusions: The risk of VTE amongst patients hospitalised for cancer varies greatly by cancer site, age, proximity from hospital admission, and chemotherapy administration.

Keyword: Cancer, Venous thrombosis, Hospitalisation, Epidemiology, Chemotherapy

\section{Background}

Venous thromboembolism (VTE) is responsible for approximately 25,000 deaths each year in the UK, and it is well established that patients with cancer are at higher risk of VTE compared to the general population [1-3]. The estimated annual incidence of VTE in the cancer population is $1.3 \%$, and the risk of death is higher for cancer patients with VTE than for those without [4-8]. Given the ageing population and increased early diagnosis, more people are living with cancer in the UK than ever before [9]. Therefore, the prevention of a potentially fatal cancer-associated VTE amongst patients is of paramount importance. Furthermore, the long-term consequences of

\footnotetext{
*Correspondence: sonia.ratib@nottingham.ac.uk

${ }^{1}$ Centre of Evidence Based Dermatology, King's Meadow Campus, Lenton

Lane, University of Nottingham, Nottingham NG7 2RN, UK

Full list of author information is available at the end of the article
}

VTE such as post-thrombotic syndrome (PTS) are more of an issue now as people with cancer are living long enough now to develop them. The cost to the NHS for management of PTS is significant and covered in the Department of Health enquiring into VTE [1].

Current UK guidelines, published by the National Institute for Health and Care Excellence (NICE), recommend prophylaxis for VTE for cancer patients admitted to hospital, but only routinely to those hospitalised for 3 or more days or who are expected to have ongoing reduced mobility [10]. Prophylaxis is cheap and highly effective (around 50 to $70 \%$ reduction) [11, 12]; however, to prevent unnecessary harm from thromboprophylaxis and its associated adverse effects, careful consideration must be given to identify patients who are most at risk so that prophylaxis can be appropriately targeted. 
Previous studies and a recent report from the Centers for Disease Control and Prevention confirm hospitalisation is an important risk factor for VTE and emphasise the need for greater awareness of VTE risks and implementation of preventative measures in hospital [13, 14]. To date, a limited number of hospital-based studies in patients with cancer (outside of the UK only) have been conducted, and the majority of studies did not determine the risk of VTE following discharge [15-18]. Of the two that did, one study was limited to a select patient group and the other did not determine how the risk of re-admission for VTE varies by potential risk factors $[15,16]$.

There is therefore a need for a hospital-based cohort study in patients with cancer in England to determine contemporary and precise estimates of the risk of VTE, taking into account risk factors such as age, cancer site, proximity from admission and chemotherapy administration. Such risk stratification could be used to inform future clinical guidelines and optimise the use of prophylactic anticoagulation when patients are admitted to hospital with cancer.

This study uses the English Hospital Episode Statistics (HES) and linked Office for National Statistics (ONS) death certificate data to determine the risk of VTE in hospitalised cancer patients, during admission and postdischarge, and stratified by risk factors.

\section{Methods}

\section{Data source and patients}

We conducted a cohort study using the Hospital Episode Statistics (HES) database, which contains details on all inpatient (except accident and emergency) and day case admissions to English NHS hospitals from 1989. More than 12 million admission records are added each year [19]. The database is managed by the Health and Social Care Information Centre and contains data on hospitalisations, which are broken down into periods of care seen by consultants (episodes). The primary diagnosis (the main reason the patient is receiving care) per episode is indicated along with all secondary diagnoses (any relevant comorbidities and illnesses acquired whilst in hospital). A diagnosis is coded using the ICD-10 (International Classification of Diseases, 10th revision), and all procedures which take place during the admission are coded using the OPCS-4 (Office of Population, Censuses and Surveys' classification of surgical operations and procedures, fourth revision). HES is linked to the ONS death registry which provides the date of death for all deceased patients.

We selected patients who had a first cancer diagnosis recorded in HES (ICD-10 Chapter II, C00-C97, excluding non-melanoma skin cancer) between 1 January 1998 and 31 October 2012, as this was the period the HES data were available for at the time of writing. Patients who had a VTE event were identified. Patients were excluded if:
- Under 18 years of age at first cancer diagnosis

- Had a VTE diagnosis in a hospital admission prior to the cancer admission

Data were analysed separately for the 24 most common cancer sites (based on 2007 UK incidence data). Cancer sites not included within these were categorised as 'Other'. 'Unknown primary' site consisted of metastatic cancers with no known primary cancer site (C77-C80). Cancer site classification was based on the first occurring cancer, and the corresponding date was assumed to be the date of diagnosis (termed index date from this point onwards). Ethical approval was given by the ONS for this study (reference number RU863/NIC-165667-FH1W1).

\section{VTE event}

For the cancer patients, a VTE diagnosis was defined as (i) having a hospital admission for pulmonary embolism (ICD-10, I26) or venous thrombosis (ICD-10, I80, I81 or I82), (ii) a diagnosis with one of the above codes during a hospital admission for another reason and (iii) having one of the above codes as underlying cause of death. The first VTE event concurrent with or following the index date was selected as the outcome of interest.

\section{Chemotherapy}

Patients receiving inpatient therapy were identified using OPCS-4 codes for chemotherapy (X72.1, X72.2, X72.3 and X73.1).

\section{Statistical methods}

The risk of VTE was stratified by timing of the first VTE event, that is, whether the event occurred during the same hospitalisation as the index date or as re-admission in the 6 months following discharge, for all 24 cancers sites. Further stratification by age-group $(<60,60-80$ and $>80$ years $)$ was performed for the four most commonly diagnosed cancers in the UK (breast, lung, bowel and prostate), those found to be at high risk of VTE (according to our data) and all cancers combined. The relative risk of first VTE as a re-admission within 6 months from discharge amongst those who had a record of chemotherapy compared to those who did not was determined using logistic regression, for all cancer sites.

Trends in VTE risk over time (assigning patients to year of index date) were investigated for the four most commonly diagnosed cancers. Patients whose first VTE event was concurrent with their index date were removed from this analysis to ensure the VTE event was subsequent to the cancer diagnosis. Patients whose index date was in 2012 were also excluded from this part of the analysis as data were not available for the full calendar year. To control for differing length of hospital stay (a marker of cancer severity), we repeated the analysis stratified by 
short-term ( $<3$ days) and prolonged stay ( $\geq 3$ days). This cutoff was chosen according to NICE VTE guidelines (NICE guidelines, 2010). We also conducted a sensitivity analysis to determine if trends for the whole cohort were different to the subgroup of patients whose primary diagnosis was cancer.

In addition to risk, absolute rates of VTE were determined to account for varying length of survival by type of cancer. The rates were presented by cancer site and timing of VTE event in relation to hospitalisation: during hospitalisation or 6 months post-discharge. Person-time at risk commenced at the time of index date or time from discharge for each respective group. Patients were followed up until they developed a VTE event, died, 6 months postdischarge, or 31 October 2012 (last data collection date), whichever was earliest. Rates were calculated as the number of first VTE events divided by person-time (per 1000 person-years). VTE events concurrent with start of follow-up were excluded (as these patients did not contribute person-time years). All data management and statistical analysis were performed using Stata 12 (Statacorp, 4905 Lakeway Drive, College Station, Texas 77845, USA).

\section{Results}

\section{Patients}

A total of 3,558,680 patients were identified with a hospital admission for cancer between 1998 and 2012. The median age at index date was 70 (IQR 59.6, 78.7) years. Of these patients, 108,770 (3.06 \%) had a VTE anytime between index date and up to 6 months from discharge; just under two-thirds of these ( $n=66,954 ; 61.6 \%)$ had their first VTE during the hospitalisation for cancer (Table 1). Of the 155,650 patients who had a VTE any time during the study period, $n=70,725(45.4 \%)$ had a PE and $n=84,925$ (54.6\%) had a DVT as their first VTE event. There were 6235 (4 \%) patients who died from their VTE during the study period and the median (interquartile range) followup time was $1.6(0.31,4.40)$ years.

\section{Risk of first VTE by cancer site and timing from index date}

For the majority of cancers, the risk of VTE during hospitalisation was higher than in the first 6 months postdischarge (1.88 vs. $1.42 \%$ respectively, overall) (Table 2 ). The cancer sites with the highest proportion of VTE events during initial hospitalisation for cancer were pancreatic $(4.89 \%)$, ovarian $(4.01 \%)$ and liver (3.84 \%). In contrast, VTE occurred in less than $0.5 \%$ of patients with malignant melanoma, oral and laryngeal cancer. Of the 2,943,792 patients alive at discharge and without a prior VTE event, the three cancer sites with the highest risk of a VTE within 6 months were pancreatic (3.66\%), oesophagus (2.98\%) and stomach (2.84\%).
Table 1 Patient characteristics

\begin{tabular}{lll}
\hline Characteristic & No. of patients $^{\mathrm{a}}$ & $\%$ \\
\hline Sex & & \\
$\quad$ Male & $1,803,145$ & 50.7 \\
$\quad$ Female & $1,755,535$ & 49.3 \\
Age at first cancer diagnosis (years) & & \\
$\quad 18-40$ & 154,617 & 4.3 \\
$41-60$ & 761,059 & 21.4 \\
$61-80$ & $1,879,373$ & 52.8 \\
$>80$ & 763,631 & 21.5 \\
Mean (SD) & $68.2(14.3)$ & \\
Median (IQR) & $70(59.6,78.7)$ & \\
Follow-up time (years) & & \\
Total & $12,028,985$ & \\
Median (IQR) & $1.70(0.33,5.46)$ & \\
& &
\end{tabular}

First VTE event

$\begin{array}{lll}\text { During hospitalisation } & 66,954 & 43.02^{\mathrm{b}} \\ \text { Within } 6 \text { months following discharge } & 41,816 & 26.87^{\mathrm{b}} \\ \text { Beyond } 6 \text { months following discharge } & 46,880 & 30.12^{\mathrm{b}} \\ \text { Entire study } & 155,650 & \end{array}$

$S D$ standard deviation, IQR interquartile range

a Unless otherwise stated

${ }^{\mathrm{b}}$ Total number of patients who had a VTE during the entire study

Risk of VTE by age and timing from index date

For all cancers combined, the risk increased from $1.4 \%$ in those less than 60 years to $2.3 \%$ in those over 80 years (Table 3). However, for the cancers we considered with a poor prognosis (lung, liver and pancreatic), the risk of VTE during hospitalisation decreased with age.

\section{Trends of VTE by calendar year}

Figures 1 and 2 display the risk of VTE during hospitalisation and within 6 months of discharge, respectively, by year of index date. With respect to the risk during hospitalisation, the trends varied by cancer site. Overall, the risk decreased with time, especially for breast and prostate cancer. In contrast, for lung cancer, the risk of VTE increased between 1998 and 2008. With respect to the risk of VTE as a re-admission, there was an overall increase over the calendar period. The increase was relatively small for breast and prostate but significant for lung and bowel, increasing twofold for lung and just over $50 \%$ for bowel from 1998 to 2011.

Trends of VTE by calendar year stratified by length of stay When stratified by hospital duration, the reduction of VTE over time is less pronounced for breast cancer but the rise amongst lung cancer patients still remains (Additional file 1: Figure S1). Trends by length of stay were similar between the overall cohort (Additional file 1: Figure S1) 
Table 2 First VTE event (\%) stratified by cancer site and timing of event, up to 6 months from discharge

\begin{tabular}{|c|c|c|c|c|c|c|c|c|c|}
\hline \multirow{2}{*}{$\begin{array}{l}\text { First VTE event } \\
\text { Cancer site }\end{array}$} & \multicolumn{3}{|c|}{ During hospitalisation } & \multicolumn{3}{|c|}{ Within 6 months following discharge } & \multicolumn{3}{|l|}{ Total } \\
\hline & No. of people & No. with VTE & $\%$ & $\begin{array}{l}\text { No. of people alive } \\
\text { at discharge \& no } \\
\text { previous VTE }\end{array}$ & No. with VTE & $\%$ & & No. with VTE & $\%$ \\
\hline Breast & 525,053 & 4843 & 0.92 & 485,009 & 3643 & 0.75 & 525,053 & 8486 & 1.62 \\
\hline Lung & 395,671 & 9808 & 2.48 & 278,182 & 6436 & 2.31 & 395,671 & 16,244 & 4.11 \\
\hline Bowel & 432,308 & 7369 & 1.70 & 364,489 & 5635 & 1.55 & 432,308 & 13,004 & 3.01 \\
\hline Prostate & 384,078 & 5876 & 1.53 & 335,231 & 2191 & 0.65 & 384,078 & 8067 & 2.10 \\
\hline Non-Hodgkin lymphoma & 134,096 & 2979 & 2.22 & 113,989 & 2155 & 1.89 & 134,096 & 5134 & 3.83 \\
\hline Malignant melanoma & 86,496 & 318 & 0.37 & 82,445 & 155 & 0.19 & 86,496 & 473 & 0.55 \\
\hline Bladder & 241,152 & 2057 & 0.85 & 217,217 & 1547 & 0.71 & 241,152 & 3604 & 1.49 \\
\hline Kidney & 73,273 & 2229 & 3.04 & 60,755 & 724 & 1.19 & 73,273 & 2953 & 4.03 \\
\hline Oesophageal & 98,668 & 1395 & 1.41 & 79,812 & 2379 & 2.98 & 98,668 & 3774 & 3.82 \\
\hline Stomach & 86,454 & 2044 & 2.36 & 66,314 & 1886 & 2.84 & 86,454 & 3930 & 4.55 \\
\hline Pancreatic & 78,579 & 3846 & 4.89 & 52,296 & 1915 & 3.66 & 78,579 & 5761 & 7.33 \\
\hline Leukaemia & 108,405 & 1913 & 1.76 & 86,648 & 928 & 1.07 & 108,405 & 2841 & 2.62 \\
\hline Uterus & 74,346 & 1113 & 1.50 & 68,516 & 705 & 1.03 & 74,346 & 1818 & 2.45 \\
\hline Ovarian & 70,613 & 2834 & 4.01 & 57,162 & 1314 & 2.30 & 70,613 & 4148 & 5.87 \\
\hline Oral & 69,827 & 301 & 0.43 & 62,784 & 378 & 0.60 & 69,827 & 679 & 0.97 \\
\hline Brain & 69,362 & 1545 & 2.23 & 55,107 & 1353 & 2.46 & 69,362 & 2898 & 4.18 \\
\hline Multiple myeloma & 59,610 & 1058 & 1.77 & 48,944 & 1033 & 2.11 & 59,610 & 2091 & 3.51 \\
\hline Liver & 52,242 & 2005 & 3.84 & 36,485 & 783 & 2.15 & 52,242 & 2788 & 5.34 \\
\hline Cervix & 33,618 & 530 & 1.58 & 30,596 & 459 & 1.50 & 33,618 & 989 & 2.94 \\
\hline Laryngeal & 25,918 & 127 & 0.49 & 22,879 & 86 & 0.38 & 25,918 & 213 & 0.82 \\
\hline Testicular & 22,985 & 172 & 0.75 & 22,481 & 201 & 0.89 & 22,985 & 373 & 1.62 \\
\hline Bone/connective tissue & 30,023 & 483 & 1.61 & 26,490 & 293 & 1.11 & 30,023 & 776 & 2.58 \\
\hline Thyroid & 22,718 & 122 & 0.54 & 21,368 & 56 & 0.26 & 22,718 & 178 & 0.78 \\
\hline Mesothelioma & 22,354 & 361 & 1.61 & 17,350 & 349 & 2.01 & 22,354 & 710 & 3.18 \\
\hline Other site & 102,771 & 1792 & 1.74 & 87,853 & 1190 & 1.35 & 102,771 & 2982 & 2.90 \\
\hline Unknown & 258,040 & 9834 & 3.81 & 163,390 & 4022 & 2.46 & 258,040 & 13,856 & 5.37 \\
\hline Total & $3,558,660$ & 66,954 & 1.88 & $2,943,792$ & 41,816 & 1.42 & $3,558,660$ & 108,770 & 3.06 \\
\hline
\end{tabular}

Table 3 First VTE event (\%) during hospitalisation stratified by cancer site and age-group

\begin{tabular}{|c|c|c|c|c|c|c|c|c|c|}
\hline \multirow{3}{*}{$\begin{array}{l}\text { Cancer site } \\
\text { During hospitalisation }\end{array}$} & \multicolumn{9}{|l|}{ Age (years) } \\
\hline & \multicolumn{3}{|l|}{$<60$} & \multicolumn{3}{|l|}{$60-80$} & \multicolumn{3}{|l|}{$>80$} \\
\hline & No. of people & No. with VTE & $\%$ & No. of people & No. with VTE & $\%$ & No. of people & No. with VTE & $\%$ \\
\hline Breast & 231,286 & 1166 & 0.50 & 220,311 & 2112 & 0.96 & 73,456 & 1565 & 2.13 \\
\hline Lung & 60,594 & 1820 & 3.00 & 249,044 & 5775 & 2.32 & 86,033 & 2213 & 2.57 \\
\hline Bowel & 76,305 & 984 & 1.29 & 247,306 & 4068 & 1.64 & 108,697 & 2317 & 2.13 \\
\hline Prostate & 32,460 & 255 & 0.79 & 239,913 & 3516 & 1.47 & 111,705 & 2105 & 1.88 \\
\hline Ovarian & 25,834 & 740 & 2.86 & 34,245 & 1527 & 4.46 & 10,534 & 567 & 5.38 \\
\hline Pancreatic & 13,278 & 700 & 5.27 & 44,386 & 2259 & 5.09 & 20,915 & 887 & 4.24 \\
\hline Liver & 11,020 & 514 & 4.66 & 28,717 & 1101 & 3.83 & 12,505 & 390 & 3.12 \\
\hline All cancers & 915,676 & 12,787 & 1.40 & $1,879,373$ & 36,692 & 1.95 & 763,631 & 17,475 & 2.29 \\
\hline
\end{tabular}




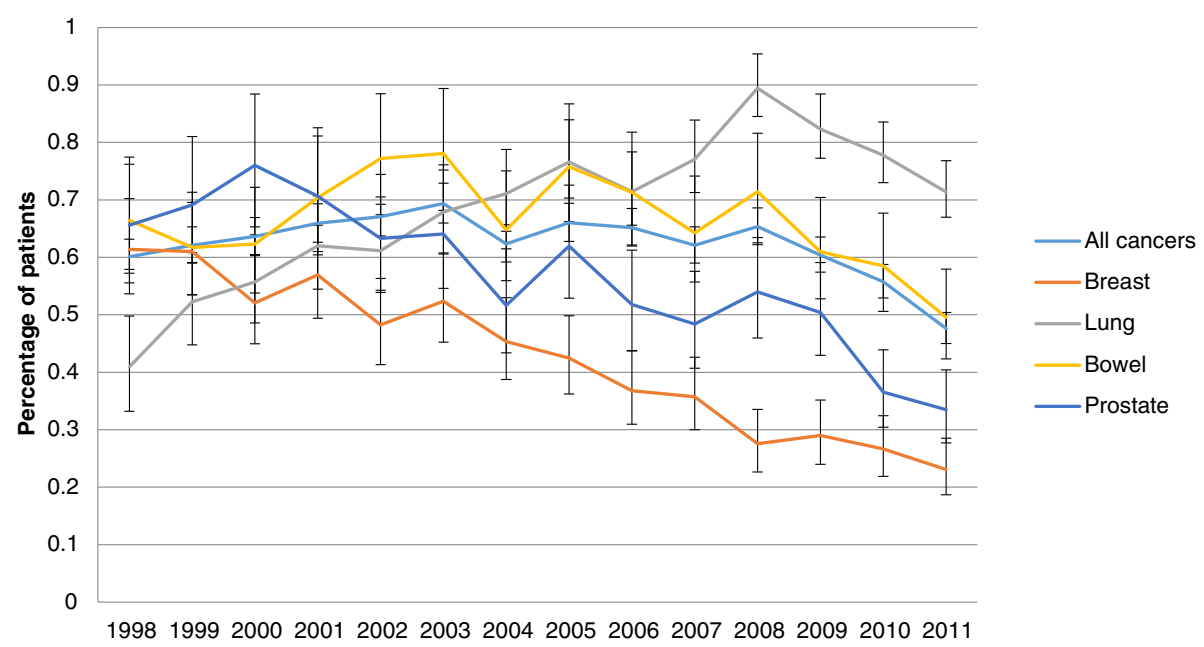

Fig. 1 Percentage of patients with first VTE during hospitalisation by year of cancer diagnosis

and the subgroup of patients whose primary diagnosis was cancer (Additional file 2: Figure S2).

\section{Risk of VTE by chemotherapy}

Of the study population, a total of 719,257 patients (20.2\%) received inpatient chemotherapy during the study period and the median time from index date to chemotherapy was 46 (IQR 16, 104) days. The number of people who received chemotherapy during their initial hospitalisation was 250,638 (7\%). Of those who were discharged without a VTE, and followed-up for up to 6 months, $22.7 \%$ received chemotherapy (Table 4). For these patients, the odds ratio of VTE in those who underwent chemotherapy compared to those who did not was 1.75 (95 \% CI 1.72, 1.79). The cancer sites associated with the highest risk of VTE within 6 months from discharge, if chemotherapy was undertaken, were pancreatic (5.2\%), stomach (4.87\%) and oesophageal $(4.67 \%)$. The cancer sites with the highest risk of VTE amongst patients not receiving chemotherapy were pancreatic (3.20\%), brain (2.52 \%) and ovarian (2.43\%). For all cancer sites, except brain, ovarian, multiple myeloma and oral cancer, the proportion of chemotherapy patients who had a VTE event was statistically significantly higher than those who did not undergo treatment ( $p<0.05$ for all instances).

\section{VTE rates by cancer site and timing from index date}

For all cancer sites, the absolute rate of VTE was higher during hospitalisation compared with rates in the first 6 months following discharge. In the first 6 months following discharge, the cancer sites associated with the highest rates were pancreatic (11.9 per 1000 person-years; CI 11.3-12.4), oesophageal (7.8; CI 7.4-8.1) and lung (6.8; CI 6.7-7.0). The overall rate of VTE was 3.34 per 1000 person-years (95 \% CI 3.31-3.37). (Additional file 3: Figure S3).

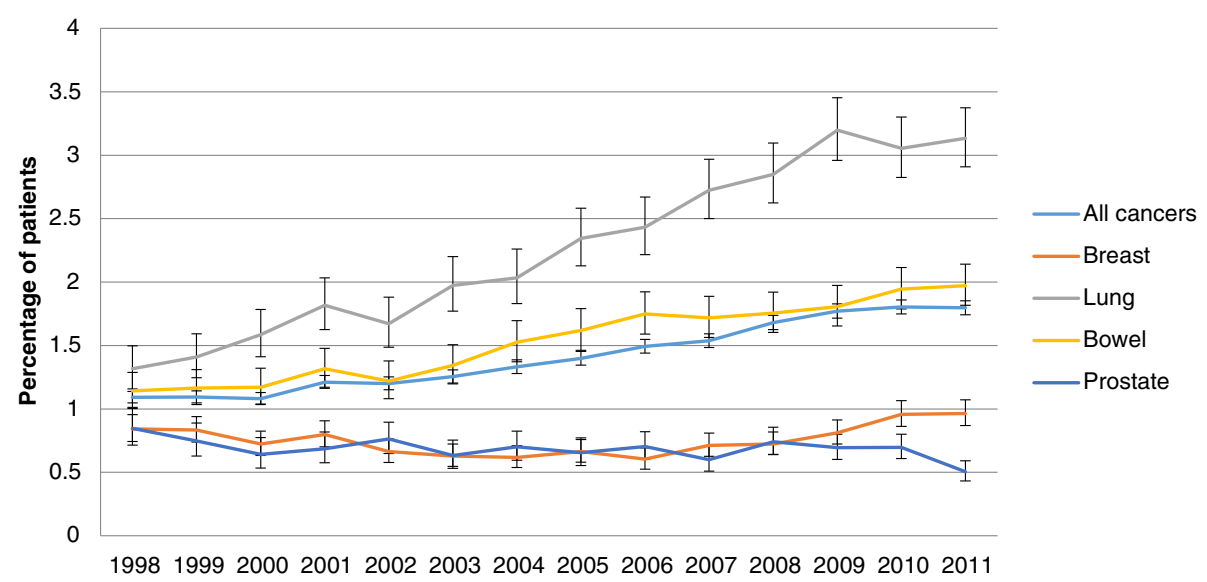

Fig. 2 Percentage of patients with first VTE within 6 months following discharge by year of cancer diagnosis 
Table 4 First VTE event within 6 months from discharge (\%) stratified by cancer site and chemotherapy

\begin{tabular}{|c|c|c|c|c|c|c|c|}
\hline Cancer site & $\begin{array}{l}\text { No. of people alive and no } \\
\text { VTE during hospitalisation }\end{array}$ & Chemotherapy & VTE & $\%$ & No chemotherapy & VTE & $\%$ \\
\hline Breast & 485,009 & 138,776 & 1871 & 1.35 & 346,233 & 1772 & 0.51 \\
\hline Lung & 278,182 & 71,155 & 2389 & 3.36 & 207,027 & 4047 & 1.95 \\
\hline Bowel & 364,489 & 96,577 & 1853 & 1.92 & 267,912 & 3782 & 1.41 \\
\hline Prostate & 335,231 & 17,687 & 180 & 1.02 & 317,544 & 2011 & 0.63 \\
\hline Non-Hodgkin lymphoma & 113,989 & 60,495 & 1165 & 1.93 & 53,494 & 990 & 1.85 \\
\hline Malignant melanoma & 82,445 & 4088 & 20 & 0.49 & 78,357 & 135 & 0.17 \\
\hline Bladder & 217,217 & 32,418 & 291 & 0.90 & 184,799 & 1256 & 0.68 \\
\hline Kidney & 60,755 & 4458 & 61 & 1.37 & 56,297 & 663 & 1.18 \\
\hline Oesophageal & 79,812 & 22,786 & 1063 & 4.67 & 57,026 & 1316 & 2.31 \\
\hline Stomach & 66,314 & 14,916 & 726 & 4.87 & 51,398 & 1160 & 2.26 \\
\hline Pancreatic & 52,296 & 12,015 & 625 & 5.20 & 40,281 & 1290 & 3.20 \\
\hline Leukaemia & 86,648 & 23,957 & 287 & 1.20 & 62,691 & 641 & 1.02 \\
\hline Uterus & 68,516 & 7615 & 146 & 1.92 & 60,901 & 559 & 0.92 \\
\hline Ovarian & 57,162 & 28,259 & 613 & 2.17 & 28,903 & 701 & 2.43 \\
\hline Oral & 62,784 & 12,080 & 114 & 0.94 & 50,704 & 264 & 0.52 \\
\hline Brain & 55,107 & 6726 & 135 & 2.01 & 48,381 & 1218 & 2.52 \\
\hline Multiple myeloma & 48,944 & 18,175 & 348 & 1.91 & 30,769 & 685 & 2.23 \\
\hline Liver & 36,485 & 5228 & 155 & 2.96 & 31,257 & 628 & 2.01 \\
\hline Cervix & 30,596 & 7651 & 177 & 2.31 & 22,945 & 282 & 1.23 \\
\hline Laryngeal & 22,879 & 2711 & 15 & 0.55 & 20,168 & 71 & 0.35 \\
\hline Testicular & 22,481 & 9119 & 103 & 1.13 & 13,362 & 98 & 0.73 \\
\hline Bone/connective tissue & 26,490 & 4231 & 78 & 1.84 & 22,259 & 215 & 0.97 \\
\hline Thyroid & 21,368 & 717 & 3 & 0.42 & 20,651 & 53 & 0.26 \\
\hline Mesothelioma & 17,350 & 4908 & 120 & 2.44 & 12,442 & 229 & 1.84 \\
\hline Other site & 87,853 & 36,920 & 476 & 1.30 & 50,933 & 714 & 1.40 \\
\hline Unknown & 163,390 & 25,095 & 1128 & 4.49 & 138,295 & 2894 & 2.09 \\
\hline Total & $2,943,792$ & 668,763 & 14,142 & 2.11 & $2,275,029$ & 27,674 & 1.22 \\
\hline
\end{tabular}

\section{Discussion}

\section{Main findings}

We found that more people developed VTE in their initial hospitalisation than in the subsequent 6 months, for most cancer types. Regardless of how we assessed VTE, pancreatic cancer was associated with the highest risk of VTE of all measured cancer types, both overall and specifically amongst those who underwent chemotherapy. The overall risk of VTE in people hospitalised for cancer was $3.06 \%$ and overall varied from $1.88 \%$ during hospitalisation to $1.42 \%$ within 6 months from discharge; in those with pancreatic cancer, the equivalent risk was 4.89 and $3.66 \%$, respectively. For cancer types with a poor prognosis (e.g., lung), there was a negative association between age and risk of VTE. For most cancer types, the risk of VTE within 6 months from discharge was higher amongst those who received chemotherapy than those who did not. Compared with previous work, we found important differences in time trends depending on whether VTE was assessed during the initial hospitalisation or in the ensuing 6 months. In particular, readmission rates for VTE from 1998 to 2011, increased by twofold in patients with lung cancer and $50 \%$ in those with bowel cancer.

\section{Strengths and limitations}

This is the first study to describe the risk of VTE in a hospitalised cancer population in the UK and is one of the largest studies worldwide on this topic. The large sample size gives precise risk estimates stratified by cancer type, including those of lower prevalence. As the HES database incorporates all inpatient and day case hospital admissions taking place in England, our results are nationally generalisable. Moreover, we have been able to distinguish VTE events which were recorded during the cancer admission from those recorded in re-admissions over the subsequent 
6 months, providing novel information that can be used in a clinical setting.

Our study has several weaknesses. First, is the lack of detail in HES to establish whether VTE is the cause or consequence of hospitalisation when assessing VTE as baseline. This is a limitation inherent in all hospital-based studies using discharge notes, as primary diagnosis is not necessarily the reason for hospitalisation. Second is the reliability of the diagnostic coding for VTE in HES. This is in terms of sensitivity, as not all VTE events may be recorded in secondary care, as well as specificity, as data to support a VTE diagnosis, such as evidence of anticoagulant treatment, are not available in HES. As we did not have access to outpatient data, and given that the majority of cancer-associated VTE is diagnosed and managed as an outpatient [20], our estimates of the risk of VTE postdischarge are most probably underestimated. Thus, the true burden of VTE in hospitalised cancer patients postdischarge may be greater than we report. However, as VTE events occurring during an inpatient admission would be fully recorded, we do not believe that our rates of VTE during hospitalisation will be underestimated. Third, our study is only able to assess the risk of VTE in people who are hospitalised for cancer, so these results cannot be applied to patients not hospitalised for their cancer (for instance those who die without ever being hospitalised).

Similar to previous studies, we lack information on potential confounders such as stage of disease and comorbidity which have been shown to be associated with risk of VTE. These variables could explain why patients with certain cancer types, and those undergoing chemotherapy, have a higher risk of VTE than others $[14,20]$. Finally, as in the case of other studies, it is likely that we have underestimated the number of people receiving chemotherapy as we have only included therapy during hospital admission.

\section{Comparison with other studies}

This current study is consistent with the findings of previous work, that pancreatic cancer is associated with the highest risk of VTE amongst patients hospitalised for cancer [16-18]. With respect to the risk of VTE during hospitalisation, Stein et al. [17] found a similar finding of $2 \%$ risk of VTE in patients hospitalised for cancer between 1979 and 1999. However, a US-based cohort study by Khorana et al. [18] reported a $4.1 \%$ overall risk of VTE during hospitalisation, almost double the risk we report. The risk of VTE may be higher in the USA compared to the UK due to true population differences or different case ascertainment and/or use of prophylaxis. The studies by Levitan et al. [15] and a separate US study specifically including patients with neutropenia (Khorana et al. [16]) both demonstrated that the risk of re-admission for VTE is smaller than during initial hospitalisation, similar to this current study This could be a result of comorbidities, infections, lack of mobility or the effect of various treatments during hospitalisation, which are all associated with risk of VTE or the aforementioned potential for under recording of VTE events occurring post-discharge [21-26].

With respect to the association between age and risk of VTE in cancer patients, there are inconsistent findings in the literature $[16,18,27]$. We have found, in general, that risk of VTE increases with age during initial hospitalisation, apart from cancers with a poor prognosis. The former could be due to increasing baseline risk of VTE with age. The latter finding could be due to older patients with a poor prognosis being more likely to die before having a VTE than younger patients.

Regarding the effect of treatment on the risk of VTE, the study by Khorana et al. [18] is the only previous hospitalbased study to examine the association between VTE event and chemotherapy and also found the risk of VTE was higher amongst patients who underwent chemotherapy, than those who did not. However, because the study was not prospective, they were unable to explore the risk of readmission of VTE, neither were results for chemotherapy stratified by cancer type. In our study, we included episodes of chemotherapy delivered in subsequent day case admissions and as such would have captured this information more comprehensively. This could explain why we found a higher proportion of patients undergoing chemotherapy [18].

To our knowledge, only one study has stratified rates by cancer site and demonstrated how the increase in rates over calendar period was higher in those with a greater rate of VTE [27]. In addition to this, we have demonstrated that the trends in VTE vary not only by cancer site but whether the VTE event occurred during hospitalisation (adjusting for length of stay) or following discharge, with subsequent VTE in patients with cancers of the lung having increased markedly over the 14-year study period.

\section{Clinical implications}

Given that our study and others highlight the varying risk of VTE by cancer site and the higher risk in hospital compared to post-discharge, careful consideration of the patients that would and would not benefit from prophylaxis following hospitalisation is required. For example, young patients with malignant melanoma may experience a net harm from taking in-hospital prophylaxis whereas young patients with pancreatic, lung or liver cancer may benefit. One could argue, however, that for patients with pancreatic cancer, who are at such advanced disease stage and in poor health in general, that prevention of VTE may not be cost effective as they are likely to die short term for other reasons. The relatively low risk of VTE in patients with myeloma could reflect clinicians' use of routine prophylaxis during chemotherapy as an outpatient and reflects 
results from other inpatient studies which report VTE rates in myeloma which are similar to the average for all cancer patients) $[16,18]$.

Our work adds to ongoing research investigating the association of chemotherapy with the development of VTE in patients with cancer. Such an association has been shown in several studies [2, 28-31]. For example, in one population-based case-control study, patients receiving chemotherapy had a higher odds ratio for the development of VTE (6.5) than those not receiving chemotherapy (4.1), when compared with patients without cancer [2]. Our group's recent work on VTE in breast cancer showed the risk of VTE was tenfold when chemotherapy was treated as a time-varying covariate [31]. Due to limitations of the data in this current study, we have only been able to crudely analyse the effect of chemotherapy on risk of VTE.

Khorana et al. [32] published a risk assessment model to estimate the risk of VTE in patients with cancer receiving chemotherapy (4066 patients) which has set the stage for randomised clinical trials in this area. In this risk model, cancers of the stomach and pancreas were classed as very high risk. Such a classification was supported by data from the sub-group of patients in our study who underwent chemotherapy (which took place an average of 46 days into the 6 month interval), with a high VTE risk ( $>4 \%)$ also occurring amongst people with oesophageal cancer. Such information could be used to influence the introduction of chemotherapy as a risk factor into some guidelines for specific sub-groups of patients, as has been suggested by the National Comprehensive Cancer Network [33].

We have demonstrated that trends of VTE over time vary considerably by cancer site. For example, in patients with lung cancer, the risk of VTE during hospitalisation doubled between 1998 and 2008 (even after adjusting for length of hospital stay), whereas it fell or only slightly increased for all other cancers. This rise may be explained by greater ascertainment by computerised tomography (CT) scan rather than a real rise. Patients with lung cancer are most likely to get follow-up CT scans than patients with other cancers, and there is increasing CT availability and increasing resolution of scans in the UK.

\section{Conclusions}

This is the first hospital-based study to report the risk of VTE amongst patients with cancer in the UK. When considering clinical guidelines for inpatients, cancer site may need to be taken into account, especially as the risk varies from $0.37 \%$ (malignant melanoma) to $4.89 \%$ (pancreas). There could be more of a focus on early prophylactic use amongst the high-risk cancers immediately following hospitalisation, especially amongst younger patients with pancreatic cancer, and consideration of chemotherapy, as a potential risk factor, in future clinical decision-making may be required.

\section{Additional files}

Additional file 1: Figure S1. Risk of first VTE during long stay

hospitalisation ( $\geq 3$ days) by year of cancer diagnosis. (DOCX $20 \mathrm{~kb}$ )

Additional file 2: Figure S2. Riskfirst VTE during long stay

hospitalisation ( $\geq 3$ days) by year of cancer diagnosis-primary diagnosis only. (DOCX $21 \mathrm{~kb})$

Additional file 3: Figure S3. Rate of VTE six months post-discharge by cancer site. (DOCX $18 \mathrm{~kb}$ )

\section{Abbreviations}

HES, Hospital Episode Statistics; NICE, National Institute for Health and Care Excellence; ONS, Office for National Statistics; VTE, venous thromboembolism

Acknowledgements

Not applicable.

\section{Funding}

This work was funded by the Population and Research Committee project grant C17683/A12079 from Cancer Research UK. Cancer Research UK had no role in the design of the study and collection, analysis and interpretation of data and in writing the manuscript.

\section{Availability of data and materials}

We are unable to share the dataset supporting the conclusions of this article in a public repository due to data sharing agreement restrictions. However, all data used in this article are available from the Health and Social Care Information Centre (http://www.hscic.gov.uk/DARS)".

\section{Authors' contributions}

MJG had the initial idea and designed the research study. SR conducted the analysis and wrote the first full draft of the paper. AJW contributed to the design of the study and the writing of the paper. TRC provided clinical input. All authors contributed to and approved the final draft of the paper.

\section{Competing interests}

The authors declare that they have no competing interests.

Consent for publication

Not applicable.

Ethics approval and consent to participate

Ethical approval was given by the Office for National Statistics ethical committee for this study (reference number RU863/NIC-165667-FH1W1).

Financial support

Cancer Research UK (C17683/A12079)

\section{Author details}

${ }^{1}$ Centre of Evidence Based Dermatology, King's Meadow Campus, Lenton Lane, University of Nottingham, Nottingham NG7 2RN, UK. ${ }^{2}$ School of Life Sciences, Queens Medical Centre, A Floor, West Block, Nottingham NG7 2UH, UK. ${ }^{3}$ Division of Epidemiology and Public Health, School of Medicine, University of Nottingham, Clinical Sciences Building 2, City Hospital, Nottingham NG5 1PB, UK.

Received: 13 May 2016 Accepted: 19 July 2016

Published online: 26 July 2016

\section{References}

1. House of Commons Health Committee. The prevention of venous thromboembolism in hospitalised patients. London: The Stationery Office Limited; 2005. Guideline Ref ID: HOUSEOFCOMMONS2005.

2. Heit JA, Silverstein MD, Mohr DN, Petterson TM, O'Fallon W, Melton L. Risk factors for deep vein thrombosis and pulmonary embolism: a populationbased case-control study. Arch Intern Med. 2000;160(6):809-15.

3. Blom JW, Doggen CM, Osanto S, Rosendaal FR. Malignancies, prothrombotic mutations, and the risk of venous thrombosis. JAMA. 2005;293(6):715-22. 
4. Horsted F, West J, Grainge MJ. Risk of venous thromboembolism in patients with cancer: a systematic review and meta-analysis. PLoS Med. 2012;9(7): e1001275.

5. Sørensen HT, Mellemkjær L, Olsen JH, Baron JA. Prognosis of cancers associated with venous thromboembolism. N Engl J Med. 2000;343(25): 1846-50.

6. The impact of venous thromboembolism on risk of death or hemorrhage in older cancer patients. J Gen Intern Med. 2007;22(3);321-6.

7. Anderson LA, Moore SC, Gridley G, Stone BJ, Landgren O. Concomitant and antecedent deep venous thrombosis and cancer survival in male U.S. veterans. Leuk Lymphoma. 2011;52(5):764-70.

8. Jones A, Stockton DL, Simpson AJ, Murchison JT. Idiopathic venous thromboembolic disease is associated with a poorer prognosis from subsequent malignancy. Br J Cancer. 2009;101(5):840-2.

9. Cancer Research UK website: http://www.cancerresearchuk.org [Last accessed $16^{\text {th }}$ March 2016]

10. Venous thromboembolism: reducing the risk of venous thromboembolism (deep vein thrombosis and pulmonary embolism) in patients admitted to hospital. <https://www.nice.org.uk/quidance/CG92>; 2009 [Last accessed $21^{\text {st }}$ December 2015].

11. Agnelli G, George DJ, Kakkar AK, Fisher W, Lassen MR, Mismetti P, Mouret P, Chaudhari U, Lawson F, Turpie AG, SAVE-ONCO Investigators. Semuloparin for thromboprophylaxis in patients receiving chemotherapy for cancer. $\mathrm{N}$ Engl J Med. 2012;366(7):601-9.

12. Agnelli G, Gussoni G, Bianchini C, Verso M, Mandalà M, Cavanna L, Barni S, Labianca R, Buzzi F, Scambia G, Passalacqua R, Ricci S, Gasparini G, Lorusso V, Bonizonni $\mathrm{E}$, Tonato M. Nadroparin for the prevention of thromboembolic events in ambulatory patients with metastatic or locally advanced solid cancer receiving chemotherapy: a randomised, placebo-controlled, double-blind study. Lancet Oncol. 2009;10(10):943-9.

13. Centers for Disease Controls and Prevention (CDC). Venous thromboembolism in adult hospitalisations-Unites States, 2007-2009. MMWR Morb Mortal Wkly Rep. 2012;61:401-4

14. Barba R, Zapatero A, Losa JE, Marco J, Plaza S, Canora J, Casas JM. Venous thromboembolism in acutely ill hospitalized medical patients. Thromb Res. 2010;126(4):276-9.

15. Levitan N, Dowlati A, Remick SC, Tahsildar H, Sivinski LD, Beyth R, Rimm AA. (1999) Rates of initial and recurrent thromboembolic disease among cancer patients with malignancy versus those without malignancy: risk analysis using medicare claims data.

16. Khorana AA, Francis CW, Culakova E, Fisher Rl, Kuderer NM, Lyman GH. Thromboembolism in hospitalized neutropenic cancer Patients. J Clin Oncol. 2006;24(3):484-90.

17. Stein PD, Beemath A, Meyers FA, Skaf E, Sanchez J, Olson RE. Incidence of venous thromboembolism in patients hospitalized with cancer. Am J Med. 2006;119(1):60-8.

18. Khorana AA, Francis CW, Culakova E, Kuderer NM, Lyman GH. Frequency, risk factors, and trends for venous thromboembolism among hospitalized cancer patients. Cancer. 2007;110(10):2339-46.

19. Hospital episode statistics. Avaliable at http://www.hscic.gov.uk/hes [Last accessed $16^{\text {th }}$ March 2016]

20. Spencer FA, Lessard D, Emery C, Reed G, Goldberg RJ. Venous thromboembolism in the outpatient setting. Arch Intern Med. 2007:167(14):1471-5.

21. Wun T, White RH. Venous thromboembolism in patients with acute leukemia, lymphoma, and multiple myeloma. Thromb Res. 2010;125 Suppl 2:S96-102.

22. Lopez JA, Kearon C, Lee AYY. Deep Venous Thrombosis. Hematology. 2004; 2004(1):439-456. doi:10.1182/asheducation-2004.1.439.

23. Otten HB, Mathijssen J, ten Cate H, Soesan M, Inghels M, Richel DJ, Prins $\mathrm{MH}$. Symptomatic venous thromboembolism in cancer patients treated with chemotherapy: an underestimated phenomenon. Arch Intern Med. 2004;164(2):190-4

24. Heit JA, O'Fallon W, Petterson TM, Lohse CM, Silverstein MD, Mohr DN, Melton $\sqcup$. Relative impact of risk factors for deep vein thrombosis and pulmonary embolism: a population-based study. Arch Intern Med. 2002; 162(11):1245-8.

25. Rogers MAM, Levine DA, Blumberg N, Flanders SA, Chopra V, Langa KM. Triggers of hospitalization for venous thromboembolism. Circulation. 2012 125(17):2092-9.

26. Schmidt M, Horvath-Puho E, Thomsen RW, Smeeth L, Sørensen HT. Acute infections and venous thromboembolism. J Intern Med. 2012;271(6):608-18.
27. Walker AJ, Card TR, West J, Crooks C, Grainge MJ. Incidence of venous thromboembolism in patients with cancer-a cohort study using linked United Kingdom databases. Eur J Cancer. 2013;49(6):1404-13.

28. Khorana AA, Francis CW, Culakova E, Lyman GH. Risk factors for chemotherapy-associated venous thromboembolism in a prospective observational study. Cancer. 2005;104(12):2822-9.

29. Mandalà M, Barni S, Prins M, Labianca R, Tondini C, Russo L, Milesi A, Cremonesi M, Zaccanelli M, Regonesi C, Moro C, Falanga A. Acquired and inherited risk factors for developing venous thromboembolism in cancer patients receiving adjuvant chemotherapy: a prospective trial. Ann Oncol. 2010;21(4):871-6

30. Blom JW, Vanderschoot JPM, OostindiËR MJ, Osanto S, Van Der Meer FJM, Rosendaal FR. Incidence of venous thrombosis in a large cohort of 66329 cancer patients: results of a record linkage study. J Thromb Haemost. 2006; 4(3):529-35.

31. Walker AJ, West J, Card TR, Crooks C, Kirwan CC, Grainge MJ. When are breast cancer patients at highest risk of venous thromboembolism? A cohort study using English health care data. Blood. 2016;127(7):849-57.

32. Khorana AA, Kuderer NM, Culakova E, Lyman GH, Francis CW. Development and validation of a predictive model for chemotherapy-associated thrombosis. Blood. 2008;111(10):4902-7.

33. Streiff MB, Bockenstedt PL, Cataland SR, Chesney C, Eby C, Fanikos J, Fogerty AE, Gao S, Goldhaber SZ, Hassoun H, Hendrie P, Holmstrom B, Kuderer N, Lee JT, Millenson MM, Neff AT, Ortel TL, Siddigi T, Smith JL, Yee GC, Zakarija A, McMillan N, Naganuma M. Venous thromboembolic disease. J Natl Compr Canc Netw. 2013;11(11):1402-29.

\section{Submit your next manuscript to BioMed Central and we will help you at every step:}

- We accept pre-submission inquiries

- Our selector tool helps you to find the most relevant journal

- We provide round the clock customer support

- Convenient online submission

- Thorough peer review

- Inclusion in PubMed and all major indexing services

- Maximum visibility for your research

Submit your manuscript at www.biomedcentral.com/submit 